\title{
Role of Negative Pressure Therapy in Healing of Diabetic Foot Ulcers
}

\author{
Ashraf Hassan Mohammed \\ Faculty of Physical Therapy, Cairo University, Cairo, Egypt
}

Email address:

ashsaleh1970@yahoo.com

To cite this article:

Ashraf Hassan Mohammed. Role of Negative Pressure Therapy in Healing of Diabetic Foot Ulcers. Journal of Surgery. Special Issue: Postoperative Pain Syndrome. Vol. 3, No. 2-1, 2015, pp. 31-35. doi: 10.11648/j.js.s.2015030201.17

\begin{abstract}
Thirty patients (17 female and 13 males) with chronic diabetic foot ulceration, age ranged from 50 to 65 years (53.4+ 4.1years), were selected from outpatient clinic of Benha teaching hospitals, Egypt from April 2013 to March 2014. Aim: Foot ulceration is one of the most common and severe complications of diabetes. The aim of the current was to clarify the effectiveness of topical negative pressure as a non invasive treatment approach for diabetic ulcers. Methods: Patients were divided into two equal groups; the first group was the control group and treated by traditional dressing while the second one was treated by negative pressure. The treatment course was extended up to six weeks; dressing was changed daily for the first group and day after day for the second group. Assessment was carried out before starting the course and after six weeks of treatment for both groups. The ulcer volume assessment was done by using a $10 \mathrm{~cm}$ syringe filled by terramycin ointment, and the wound surface area by using a graded plastic sheet. Student t-test was used to analyze the gained data of wound volume and surface area. Results: There was a significant improvement in the wound volume and surface area in the negative pressure group than that of the control group. Conclusion: It could be concluded that topical negative pressure is an effective noninvasive method in treating chronic diabetic foot ulceration.
\end{abstract}

Keywords: Diabetic Ulcer, Negative Pressure Therapy, Wound Measurement

\section{Introduction}

The global prevalence of diabetes, the estimated number of cases in Egypt is expected to reach 6.7 million in 2030, which places the country tenth in the list of countries with the most cases. The number of diabetic patients with foot ulceration is therefore expected to rise in Egypt. The use of new therapeutic methods may improve health-related quality of life, thereby significantly reducing overall costs and lowerextremity amputations ${ }^{(1,2)}$.

Negative pressure wound therapy (NPWT) also known as treatment with topical negative pressure (TNP) is a vacuum assisted method for ulcer care using a negative pressure of $60-125 \mathrm{~mm} \mathrm{Hg}$ on wound bed ${ }^{(3,4)}$.If excess fluid is not adequately removed from a wound after surgery, may act as both physical and chemical deterrents to healing process. TNP therapy removes excess interstitial fluid as well as transmitting a mechanical force to the surrounding tissues providing deformation of the extracellular matrix and decreasingin wound size $\mathrm{e}^{(5,6)}$.

TNP therapy deviceis a non-invasive system, where one unite delivers negative pressure to the wound bed through a drainage tube, which decompresses a sponge of polyurethane alternatively gauze in a continuous or intermittent manner ${ }^{(7,8)}$.

Negative pressure therapy decreases wound volume and depth significantly more than moist gauze dressings $(59 \%$ versus $0 \%$ and $49 \%$ versus $8 \%$, respectively $)^{(9,10)}$.TNP can be used as a primary treatment for chronic wounds or as an adjunct to surgery ${ }^{(11)}$.

\section{Materials and Methods}

Thirty patients (17 females and 13 males), with age ranged from 50-65 years suffering from chronic diabetic foot ulceration selected randomly from the outpatient clinic of Benha teaching hospitals, they were randomly divided into two equal groups. The first group (control group) was treated with traditional wound care methods while the second group (treatment group) was treated with topical negative pressure the treatment was carried out three times weekly, up to six weeks. All participants were informed about the nature and the effect of the treatment and measurement device. The patients were instructed to report any side effects during the 
treatment sessions (e.g itching, pain).

Thisstudy has been carriedout in accordance with the code of Ethics of the World Medical Association (Declaration of Helsinki) for experimentsinvolving humans, an informed consent form had been signed from each patient before participating in the study.

\subsection{Inclusive Criteria}

The patient had been chosen under the following criteria

- Both sexes shared in the study.

- Patient's age ranged from 50 to 65 years.

- Pressure ulcers; Grade III according toEuropean Pressure Ulcer Advisory Panel Grading System

- Free from immune deficiency diseases as well as collagen diseases.

- Free from blood clotting disorders as hemophilia.

- All patients received the same medical care.

\subsection{Exclusive Criteria}

Patients with the following criteria were excluded from the study

1. Malignancies or receiving radiotherapy or chemotherapy.

2. Skin diseases.

3. Deep venous thrombosis.

4. Renal failure.

5. Recent therapy with immunosuppressant or anticonvulsants.

6. Acute inflammation \& strangulated tissues.

Assessment of wound surface area was carried out by using graded plastic sheet, by equating the results by weighing the area deduced, while the wound volume was done by using a ten cubic centimeters syringe and terramycinointment for filling the area and space of ulcer to determine its volume $e^{(12)}$

\subsection{Negative Pressure Device}

VAC system $125 \mathrm{mmhg}$ (KCI negative pressure equipment).

\subsubsection{Wound Surface Area Tracing Tools}

- Sterilized transparency film.

- Fine tipped transparency permanent marker.

- Carbon and a white A4 papers.

- Metric graph paper $\left(1 \mathrm{~mm}^{2}\right)$.

\subsubsection{Wound Volume Assessment procedure}

- Using a syringe of ten cubic centimeters filled with the terramycine ointment.

- The wound is filled with the terramycine ointment

- The amount of terramycin injected into the wound was detected in cubic centimeters.

\subsection{Treatment Procedures}

- The NPWT device should be suited with pressure of 125 $\mathrm{mmHg}$, with duration of 5 minutes on and 2 minutes off.

- Dressing should be away from the boundaries of wound about 2-3 $\mathrm{mm}$. the dressing used wasa spongy dressing.

- A sterilized catheter was inserted into the dressing and connected into the device.

- The dressing was applied day after day.

\section{Results}

The patient characteristics were considered and analyzed as shown in table (1) there was no significant difference between both groups in their age, weights, and heights $(\mathrm{p}>0.05)$.

Table (1). General characteristics of patients in both groups $(A \& B)$.

\begin{tabular}{|c|c|c|c|c|c|c|c|}
\hline \multirow{2}{*}{ Items } & \multicolumn{2}{|c|}{ Control group } & \multicolumn{2}{|c|}{ Treatment group } & \multicolumn{2}{|c|}{ Comparison } & \multirow{2}{*}{$\mathbf{S}$} \\
\hline & Mean & \pm SD & Mean & \pm SD & t-value & P-value & \\
\hline Age (yrs) & 57.46 & 4.8 & 56.66 & 5.42 & 0.42 & 0.67 & NS \\
\hline Weight (Kg) & 72.0 & 9.9 & 76.0 & 11.23 & 1.03 & 0.31 & NS \\
\hline Height $(\mathrm{cm})$ & 169.46 & 6.56 & 168.73 & 6.87 & 0.29 & 0.76 & NS \\
\hline
\end{tabular}

*SD: standard deviation, P: probability, S: significance, NS: non-significant.

\subsection{Results of Wound Surface Area}

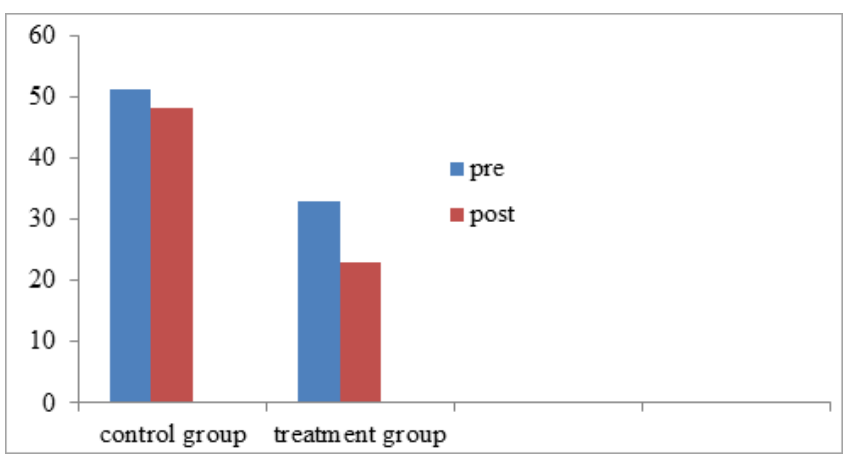

Figure (1). Mean values of pre and post-treatment measurements of wound surface area for each group.
There was a non significant improvement in wound surface area for the control group. On the other hand there was a significant improvement in the surface area of the treatment group as shown in table (2) and figure (1)

Table (2). Pre and post-treatment measurements of wound surface area for each group.

\begin{tabular}{lllll}
\hline & \multicolumn{2}{l}{ Control group } & \multicolumn{2}{l}{ Treatment group } \\
\cline { 2 - 5 } & pre & post & Pre & post \\
\hline Mean & 51.09 & 48.01 & 32.91 & 23.03 \\
ISD & 27.7 & 27.01 & 17.44 & 14.46 \\
MD & 6.56 & & 9.88 & \\
\% of improvement & $4.03 \%$ & $30.05 \%$ & \\
t-value & 7.05 & 5.74 & \\
p-value & 0.06 & 0.001 & \\
Significance & Non significant & Significant & \\
\hline
\end{tabular}


There was a non significant improvement in wound surface area for both groups pre-treatment. While the posttreatment measurement revealed a significant improvement in the treatment group than in the control group as shown in table (3) and figure (2)

Table (3). Pre and post-treatment comparison of wound surface area for both groups.

\begin{tabular}{lllll}
\hline & \multicolumn{2}{l}{ Pre-treatment } & \multicolumn{2}{l}{ Post-treatment } \\
\cline { 2 - 5 } & control & treatment & control & treatment \\
\hline Mean & 51.09 & 32.91 & 48.01 & 23.03 \\
tSD & 27.7 & 17.44 & 27.01 & 14.46 \\
MD & -18.18 & & -22.28 & \\
t-value & -1.68 & & -2.19 & \\
p-value & 0.11 & & 0.037 & \\
significance & Not significant & significant \\
\hline
\end{tabular}

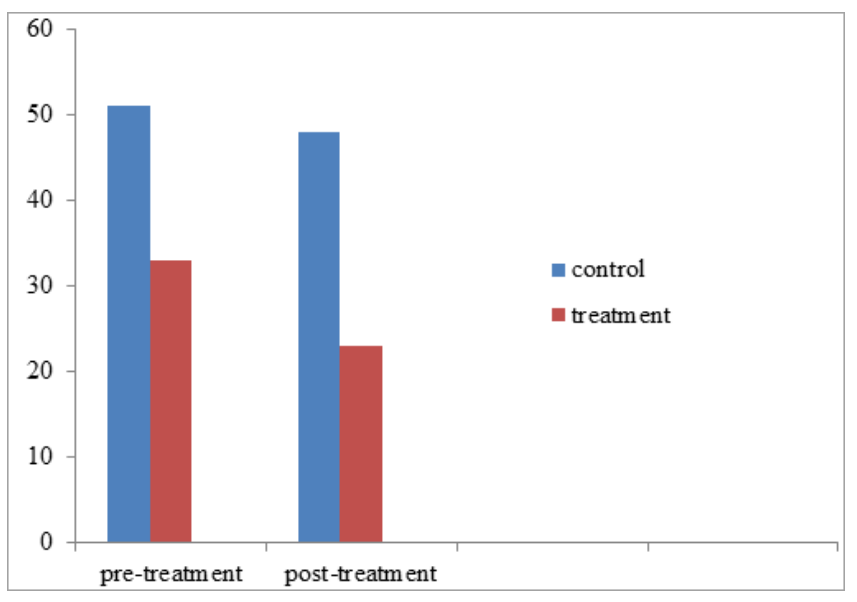

Figure (2). Mean values of pre and post-treatment comparison of wound surface area for both groups.

\subsection{Results of Wound Volume}

There was a non significant improvement in wound volume for the control group. On the other hand there was a significant improvement in wound volume of the treatment group as shown in table (4) and figure (3)

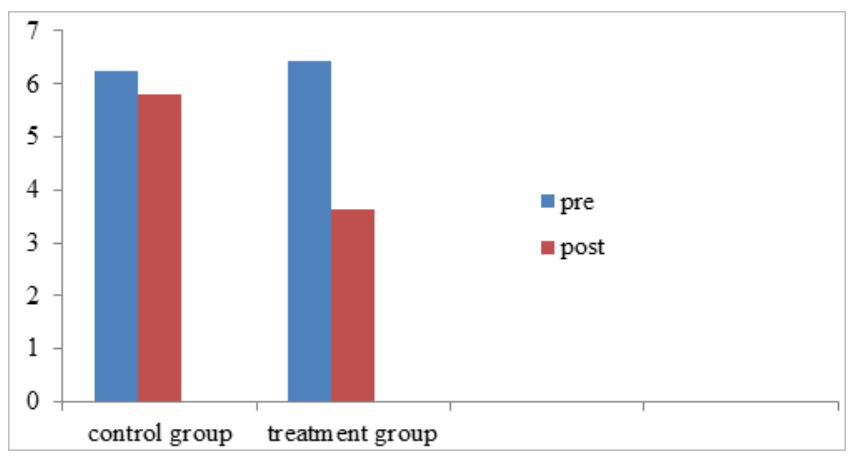

Figure (3). Mean values of pre and post-treatment measurements of wound volume for each group.
Table (4). Pre and post-treatment measurements of wound volume for each group.

\begin{tabular}{lllll}
\hline & \multicolumn{2}{l}{ Control group } & \multicolumn{2}{l}{ Treatment group } \\
\cline { 2 - 5 } & pre & post & pre & post \\
\hline Mean & 6.23 & 5.81 & 6.44 & 3.62 \\
$\pm \mathrm{SD}$ & 2.77 & 2.9 & 2.94 & 1.88 \\
MD & 0.6 & & 2.82 & \\
\% of improvement & $4.9 \%$ & & $43.78 \%$ & \\
t-value & 9.3 & 8.39 & \\
p-value & 0.07 & \multicolumn{3}{l}{0.003} \\
significance & Not significant & Significant \\
\hline
\end{tabular}

There was a non significant improvement in wound volume for both groups pre-treatment. While the posttreatment measurement revealed a significant improvement in the treatment group than in the control group as shown in table (5) and figure (4).

Table (5). Pre and post-treatment comparison of wound volume for both groups.

\begin{tabular}{lllll}
\hline & \multicolumn{2}{l}{ Pre-treatment } & \multicolumn{2}{l}{ Post-treatment } \\
\cline { 2 - 5 } & control & treatment & control & treatment \\
\hline Mean & 6.23 & 6.44 & 5.78 & 3.62 \\
$\pm \mathrm{SD}$ & 2.77 & 2.94 & 2.71 & 1.88 \\
$\mathrm{MD}$ & 0.207 & & -2.16 & \\
t-value & 0.201 & -2.54 & \\
p-value & 0.84 & 0.02 & \\
significance & Non significant & Significant \\
\hline
\end{tabular}

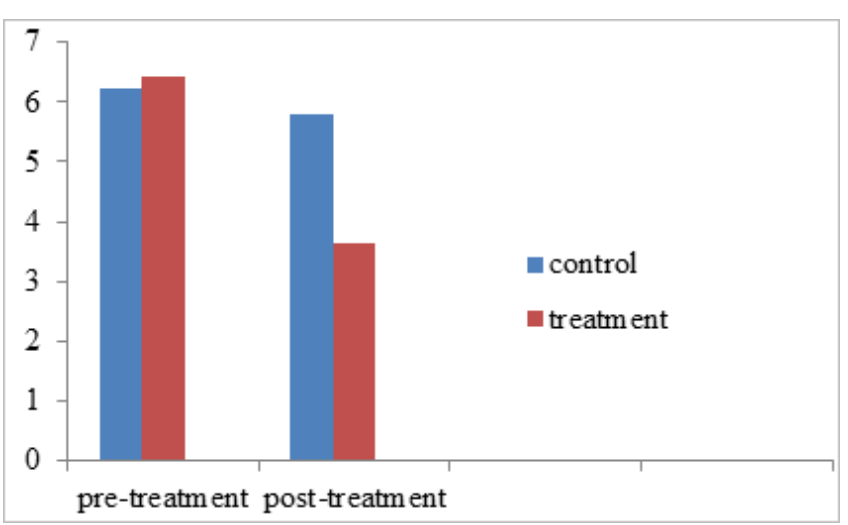

Figure (4). Mean values of pre and post-treatment comparison of wound volume for both groups.

\section{Discussion}

Foot ulceration is one of the most common and sever complications of diabetes, peripheral vascular disease, infection and the most frequent cause of hospitalization in patients with the disease. Fifteen per cent of people with diabetes will experience a chronic foot ulcer in their lifetime, and this can cause substantial emotional, physical, productivity and financial losses ${ }^{(13)}$.

Chronic lower limb ischemia becomes increasingly common with age and approximately $5 \%$ of people over 50 years have lower limb ischemia. It is more common in men with a ratio of males to females of $2: 1$. Approximately $10 \%$ of patients will progress to critical ischemia with ulceration on toes or foot and tissue loss or gangrene that requires 
urgent action to salvage the affected limb. Between $2 \%$ and $4 \%$ patients will require amputation ${ }^{(14)}$.

Negative pressure wound therapy is a vaccum assisted method for ulcer care using negative pressure of $60-125$ $\mathrm{mmHg}$ on the wound bed. The devices are non-invasive system, where one unite delivers negative pressure onto the wound bed through a drainage tube, which decompresses a sponge of polyurethane alternatively gauze in a continuous or intermittent manner. The wound fluid drain into a canister. Dressings are usually changed three times a week ${ }^{(15)}$.

Regarding to the wound surface area; the results of this study revealed that were significant decrease in surface area in the treatment group than in the control group .The significant difference between treatment and control groups could prove the efficacy of the NPWT in patients with diabetic foot ulcer.

In relation to wound volume, the results revealed a significant decrease in wound volume of treatment group than in the control group. This difference between the treatment and control groups could prove the efficacy of the NPWT in patients with diabetic foot ulcer.

The results of the current study are supported by a another one which approved that;results for patients treated with NPWT were superior to those for the patients treated with standard wound treatment, where NPWT improve the circulation in the wound and increase granulation tissue formation. These results appear to indicate that wound duration should not deter the clinician from using this modality to treat complex wounds ${ }^{(16,17)}$.

Results of the current study concerning the effect of negative pressure wound therapy in patients with diabetic foot ulcers are supported by many studies that explained the biological effects of NPWT on ulcers; as it causes micromechanical deformation as well as promotes the process of angiogenesis ${ }^{(18,19)}$.

\section{Conclusion}

It could be concluded that; negative pressure therapy is an effective, inexpensive, and non invasive method for treating chronic diabetic foot ulceration.

\section{References}

[1] Venturi ML, Attinger CE, Mesbahi AN, Hess CL, and Graw KS. Mechanisms and clinical applications of the vacuumassisted closure (VAC) device: a review. Am J Clin Dermatol2005; 6(3):185-194.

[2] Wongworawat, Schnall SB, Holtom, Moon C, and Schiller F. Negative Pressure Dressings as an Alternative Technique for the Treatment Of Infected Wounds. Clin Orthop Relat Res $2003 ; 414: 45-48$.

[3] Armstrong D.G, Lavery L.A, and Boulton A.J.M. Negative pressure wound therapy via vacuum-assisted closure following partial foot amputation: what is the role of wound chronicity. International Wound Journal 2007; 4(1): 79-86.
[4] Mendonca D.A N Negative-pressure wound therapy: a snapshot of the evidence .International Wound Journal 2006; 3(4): 261271.

[5] Beitz JM, and Bates-Jensen B. Algorithms, critical pathways, and computer software for wound care: contemporary status and future potential. Ostomy Wound Management 2001; 47:33-40.

[6] Morykwas MJ, Argenta LC, Shelton-Brown EI, McGuirt W. Vacuum-assisted closure: a new method for wound control and treatment: animal studies and basic foundation. Ann Plast Surg. 1997; 38(6):553-562.

[7] Fabian T.S., Kaufman H.J., Lett E.D. The evaluation of subatmospheric pressure and hyperbaric oxygen in ischemic full-thickness wound healing. Am Surg2000; 66:1136-43.

[8] Gustafsson R, Johnsson P, Algotsson L, et al. Vacuum-assisted closure therapy guided by C-reactive protein level in patients with deep sternal wound infection. J Thorac Cardiovasc Surg 2002; 123:895-900.

[9] Gray, M. and Peirce, B. Is negative pressure wound therapy effective for the management of chronic wounds? Evidence based report card from the center for clinical investigation. JWOCN.2004; 31: $101-105$.

[10] Joseph E, Hamori CA, Bergman S, and et al. A prospective randomised trial of vaccum-assisted closure versus standard therapy of chronic non-healing wounds. Wounds 2000; 3:60-7.

[11] Eginton MT, Brown KR, Seabrook GR, Towne JB, and Cambria RA. A prospective randomized evaluation of negative-pressure wound dressing for diabetic foot wounds. Ann Vasc Surg. 2003; 17(6):645-649.

[12] Borgquist, Ola, Ingemansson, Richard; Malmsjö, and Malin. Wound edge microvascular blood flow during negativepressure wound therapy: examining the effects of pressures from 10 to $175 \mathrm{mmHg}$.Plastic \& Reconstructive Surgery 2010; 125 (2): 502-509.

[13] Lucas C., Classen J., Harrison D., and DeHaan R): Pressure ulcer surface area measurement using instant full scale photography and transparency tracings.adv skin wound care 2002; 15(1):17-23.

[14] Frykberg, R.G., Zgonis, T., and Armstrong, D.G. Diabeticfootdisorders: A clinicalpracticeguideline. J. FootAnkle Surg.2006; 45: 50.

[15] Lazarus G, CooperD, Knighton D, Margolis D,:Definitions and guidlinesforassessment of wounds and evaluation of healing. Archives of dermatology1999; 130: 489-493.

[16] Jeschke MG, Rose C, Angele P, Fuchtmeier B, Nerlich M.N, and Bolder U. Development of new reconstructive techniques: use of Integra in combination with fibrin glue and negativepressure therapy for reconstruction of acute and chronic wounds. Plast Reconstr Surg2004 ;113(2):525-530.

[17] Peter D. A., et al: Comparison Of Negative Pressure Wound Therapy With Advanced Moist Wound Therapy In The Treatment of Diabetic Foot Ulcers: Diabetic Care 2008;31:631.

[18] Vuerstaek J.D, Vainas T, Wuite J, Nelemans P, Neumans M.H, and Veraat J.C.:State of the art treatment of chroniclegulcers: A randomisedcontrolled trial comparingvaccumassistedclosure (V.A.C.) withmodernwounddressing. J VascSurg 2006; 44(5):1029-37. 
[19] Armstrong DF, and Levary LA: Negativepressurwoundtherapyafterpartialdiabeticfootamputati on: a multicenter, randomisedcontrolled trial. Lancet 2005; 366:1704-1710. 